\title{
PREVALENCE AND PATTERN OF RHEUMATIC HEART DISEASE AMONG REPRODUCTIVE AGE GROUP FEMALE
}

Manoj Shrestha, ${ }^{1}$ Prakash Aryal ${ }^{2}$

\section{ABSTRACT}

\section{INTRODUCTION}

Rheumatic heart disease (RHD) remains a major public health problem in developing countries. In low income countries RHD accounts for approximately $90 \%$ of all cardiovascular disease among pregnant women. This study aims to evaluate the prevalence and pattern of RHD among reproductive age group women presenting to a tertiary care teaching hospital in Central Nepal.

\section{MATERIAL AND METHODS}

Prospective observational study was carried out in College of Medical Sciences Teaching Hospital, Bharatpur, Nepal from January 2019 to December 2019 by doing transthoracic echocardiography (TTE) of reproductive age group females $(n=800)$ from 15 years to 45 years of age. The data were collected in pre-structured proforma.

\section{RESULTS}

Out of 800 patients, RHD was present in $46(5.75 \%)$ patients. The incidence of RHD was found to be highest in the age group of 30-35 years 13 (28.3\%) and the mean age of presentation was 29.24 years. Mitral valve was the most common valve involvement and mitral regurgitation 37 (80.4\%) was the most common valvular dysfunction present in patients with RHD.

\section{CONCLUSION}

The prevalence of RHD among reproductive age group female is high and mitral valve is the most commonly affected valve.

\section{KEYWORDS}

Echocardiography, Mitral valve, Rheumatic heart disease.

1. Department of Cardiology, College of Medical Sciences, Bharatpur, Nepal

2. Department of Internal Medicine, College of Medical Sciences, Bharatpur, Nepal

DOI: http//doi.org/10.3126/jucms.v9i01.37975

\author{
For Correspondence \\ Dr. Manoj Shrestha \\ Department of Cardiology \\ College of Medical Sciences, Bharatpur Nepal \\ Email:drmanozshrestha@gmail.com
}




\section{INTRODUCTION}

Rheumatic heart disease (RHD) remains a major public health problem in developing countries. Cardiovascular disease complicates $1 \%$ to $3 \%$ of all pregnancies and accounts for $10 \%$ to $15 \%$ of maternal mortality. ${ }^{1}$ In low income countries RHD accounts for approximately $90 \%$ of all cardiovascular disease among pregnant women. ${ }^{2}$ For some of these women an initial diagnosis is made antenatal or postpartum, as they fail to tolerate the impact of the physiological changes of pregnancy on their damaged heart valves resulting in clinical decompensation. Symptomatic mitral stenosis (MS) has been associated with higher risk for antenatal hospital admission and approximately 50\% mortality, which occurs most commonly in the postpartum period. ${ }^{3}$ Though pregnancy for most women is uneventful, it presents unique challenges for women with RHD. Besides the impact of the pregnancy and delivery on the heart, considerations also have to be made on the impact of RHD therapy on the fetus.

Some medical therapies may be teratogenic, while surgical management in pregnancy may increase the risk of pregnancy loss. RHD, a preventable disease more common in third world country is the main cause of cardiac disability and death in younger population group. ${ }^{4}$ Prevalence of RHD varied depending upon various diagnostic criteria from $3.7 \%$ to $11.4 \%{ }^{5}$ Asymptomatic patients with valvular regurgitation tend to tolerate volumetric overload during pregnancy, patients with mitral and aortic valve stenosis are at increased risk for the development of congestive heart failure and pulmonary oedema. ${ }^{6}$ With the awareness of public health in the prevention of RHD and improvement in the healthcare system with the availability of cardiologist for evaluation and treatment of RHD, now the disease burden of RHD is rare in developed countries but still persistent in developing countries. $^{7,8}$

Echocardiographic study from Eastern part of Nepal showed high prevalence of RHD. ${ }^{9}$ The routine antenatal checkup under Nepal Government safe motherhood program doesn't include echocardiography screening as a recommendation while RHD during pregnancy is associated with increased risk of maternal and child mortality and morbidity. Limited data across Nepal but none from province number 3 are available in RHD patients regarding prevalence and patterns of valve involvement among reproductive age group female. This study aims to evaluate the prevalence and pattern of valvular involvement in rheumatic heart disease female patients of reproductive age group in a Tertiary Care Hospital of Bharatpur Nepal.

\section{MATERIAL AND METHODS}

All consecutive transthoracic echocardiography (TTE) of female reproductive age group patients from 16 years to 45 years of age and data were evaluated over a period of one year from January 2019 to December 2019 in Department of
Cardiology of College of Medical Sciences Teaching Hospital (CMSTH). The data collected included age, sex, clinical diagnosis and findings on TTE. Only first-time Echo of each patient was included for the study to avoid repetition bias. Echocardiography was done in all patients by the cardiologist of CMSTH. Diagnosis of RHD was made by echo cardiographic criteria. Other relevant investigations were done to rule out other co-morbidities. After fulfilling the inclusion criteria, female patients were enrolled in the study. Consent was taken from the Ethical Committee of CMSTH. Sample size: 800 females

\section{Inclusion criteria}

All the females in reproductive age group presenting to the Hospital for Echocardiogram.

\section{Exclusion criteria}

1. Patient with diagnosed cardiovascular diseases other than RHD,

2. Age below 16 years and above 40 years

3. Patient refused to give consent

\section{Statistical analysis}

All the data obtained by history, clinical examination and investigations as per case proforma. All the data was entered in the Microsoft excel and exported to SPSS (Statistical Package for social sciences release 20.0; SPSS, Inc; Chicago, IL) system for Windows and analyzed. Continuous variables were expressed as mean \pm SD (Standard deviation) while categorical variables were expressed as frequencies and percentages.

\section{RESULTS}

Among 800 females under study 5.75\% $(n=46)$ had RHD while $94.25 \%(n=754)$ had normal echocardiography (Figure 1).

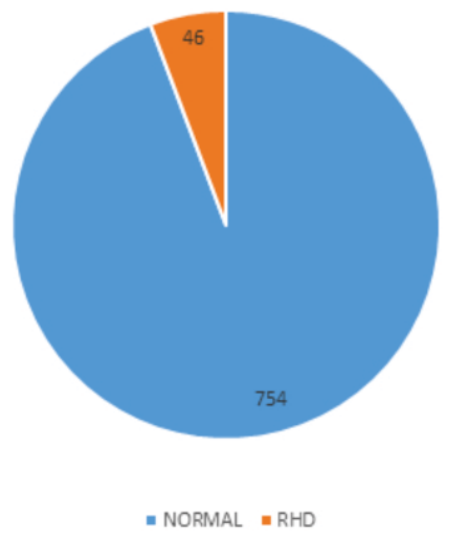

Figure 1. The figure showing prevalence of RHD among all $\operatorname{cases}(\mathbf{n}=800)$

The incidence of RHD was found to be highest in the age group of 30-35 years $13(28.3 \%)$ while lowest among the age 
group of $<20$ years $3(6.5 \%)$. Mean age of presentation was 29.24 years (Figure 2 ).

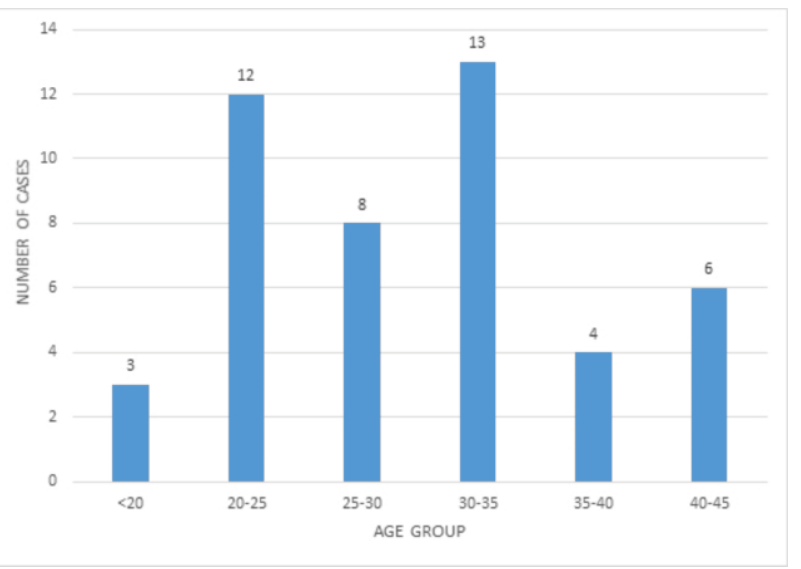

Figure 2. Age group distribution of RHD cases $(n=46)$

In this study, mitral regurgitation present in 37 (80.4\%) cases as a most common valvular involvement followed by mitral stenosis $20(43.5 \%)$, combined mitral and aortic valve involvement $13(28.3 \%)$, aortic regurgitation $11(23.9 \%)$, combined mitral regurgitation and stenosis $9(19.6 \%)$, aortic stenosis $9(8.7 \%)$ and combined aortic regurgitation and stenosis in $2(4.3 \%)$ (Figure 3$)$.

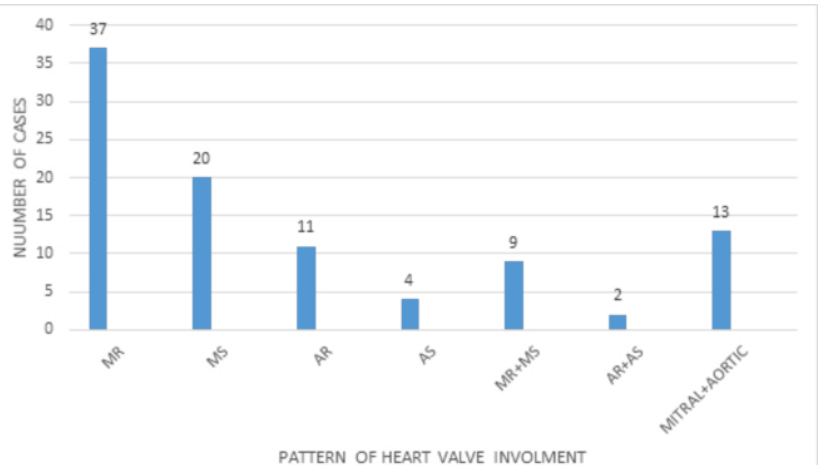

Figure 3. Frequency of isolated and mixed valvular lesions $(n=46)$

\section{DISCUSSION}

In the present study, total of 800 female patients of age group 15 to 45 years was there out of which $46(5.75 \%)$ were found to have rheumatic heart disease. In similar study done by Bhaya et $\mathrm{al}^{10}$ in 2010. The prevalence of RHD was 50.99 per thousand by Paar et $\mathrm{al}^{11}$ in 2010 the prevalence was 47.62 per thousand, Saxena et $\mathrm{al}^{12}$ found the prevalence to be 20.41 per thousand, Sanyahumbi et $\mathrm{al}^{13}$ reported in 2016 the prevalence was 33.79 per thousand, Campanale et $\mathrm{al}^{15}$ mentioned the prevalence was 32.64 per thousand in 2017 and study done by Shrestha et $\mathrm{al}^{14}$ among 5178 people in 2015, the prevalence of RHD was 10.2 per thousand.
The incidence of RHD was found to be highest in age group of $30-35$ years while lowest among age group of $<20$ years. The mean age of presentation was 29.24 years. Similar finding was found in a study done in Eastern Nepal by Shrestha et al, ${ }^{9}$ which showed women presented with RHD at mean age of 32.8 years. Another study done by Koirala et $\mathrm{al}^{16}$ in 2018 among 256 patients, the mean age was 32.8 and most commonly affected age group was $31-40$ years.

In this study, mitral regurgitation present in 37 (80.4\%) cases as a most common valvular involvement followed by mitral stenosis $20(43.5 \%)$. This study showed that regurgitant valvular disease of mitral and aortic valves was more than the stenotic lesion. Mitral valve involvement was more common than aortic in RHD patients. Similar findings were noted in study done by Kafle et al, ${ }^{17}$ Koju et al, ${ }^{18}$ Aurakzai et al, ${ }^{19}$ involving mitral regurgitation as most common and aortic stenosis was least common among the left sided valvular disease in RHD patients.

In our study, isolated mitral valve was affected more than isolated aortic valve, similar findings were found in the study done by Laudari $\mathrm{S}$ et al, ${ }^{20}$ Manjunath $\mathrm{CN}$ et al. ${ }^{21}$

The detection of valvular involvement by screening with echocardiography is helpful in early diagnosis and treatment of rheumatic heart disease preventing the progression of the disease and need for surgical management.

\section{CONCLUSION}

The prevalence of RHD was found to be $5.75 \%$ among the female of reproductive age group presenting for echocardiography with mean age of 29.24 years. Involvement of mitral valve was most common valve involvement and mitral regurgitation was most common valvular lesion. Reproductive age group female has similar prevalence of RHD to general population. The study will help to recommend the concerned authority to mandate echocardiogram test for all the reproductive age group female before pregnancy.

\section{REFERENCES}

1. Nanna M, Stergiopoulos K. Pregnancy complicated by valvular heart disease: an update. Am Hear Assoc. 2014;3(3):e000712.

2. Soler-Soler J, Galve E. Worldwide perspective of valve disease. Heart. 2000 Jun;83(6):721-5.

3. Diao M, Kane A, Ndiaye MB, Mbaye A, Bodian M, Dia MM, et al. Pregnancy in women with heart disease in sub-Saharan Africa la grossesse des femmes atteintes de cardiopathie en Afrique subsaharienne. Arch Cardiovasc Dis. 2011 Jun;104(67):370-4.

4. Ravisha MS, Tullu MS, Kamat JR. Rheumatic fever and rheumatic heart disease: clinical profile of 550 cases in India. Arch Med Res. 2003 Sep-Oct;34(5):382-7. 
5. Noubiap JJ, Agbor VN, Bigna JJ, Kaze AD, Nyaga UF, Mayosi BM. Prevalence and progression of rheumatic heart disease: a global systematic review and meta-analysis of populationbased echocardiographic studies. Sci Rep. 2019 Nov;9 (1):17022.

6. Reimold SC, Rutherford JD. Valvular heart disease in pregnancy. N Engl J Med. 2003 Jul 3;349(1):52-9.

7. Massell BF, Chute CG, Walker AM, Kurland GS. Penicillin and the marked decrease in morbidity and mortality from rheumatic fever in the United States. N Engl J Med. 1988 Feb 4;318(5):280-6.

8. Markowitz M. Pioneers and modern ideas. Rheumatic fever--a half-century perspective. Pediatrics. 1998 Jul;102(1 Pt 3):2724.

9. Shrestha NR, Pilgrim T, Karki P, Bhandari R, Basnet S, Tiwari $S$, et al. Rheumatic heart disease revisited: Patterns of valvular involvement from a consecutive cohort in Eastern Nepal. J Cardiovasc Med (Hagerstown). 2012;13:755-9.

10. Bhaya M, Panwar S, Beniwal R, Panwar RB. High prevalence of rheumatic heart disease detected by echocardiography in school children. Echocardiography. 2010;27(4):448-53.

11. Paar JA, Berrios NM, Rose JD, Cáceres M, Peña R, Pérez W, et al. Prevalence of rheumatic heart disease in children and young adults in Nicaragua. Am J Cardiol. 2010 Jun 15;105(12):180914.

12. Saxena A, Ramakrishnan S, Roy A, Seth S, Krishnan A, Misra $\mathrm{P}$, et al. Prevalence and outcome of subclinical rheumatic heart disease in India: The RHEUMATIC (Rheumatic Heart Echo Utilisation and Monitoring Actuarial Trends in Indian Children) study. Heart. 2011 Dec 15;97(24):2018-22.

13. Sims Sanyahumbi A, Sable CA, Beaton A, Chimalizeni Y, Guffey D, Hosseinipour M, et al. School and community screening shows Malawi, Africa, to have a high prevalence of latent rheumatic heart disease. Congenit Heart Dis. 2016 Nov;11(6):615-21.

14. Shrestha NR, Karki P, Mahto R, Gurung K, Pandey N, Agrawal $\mathrm{K}$, et al. Prevalence of subclinical rheumatic heart disease in Eastern Nepal: A school-based cross-sectional study. JAMA Cardiol. 2016 Apr;1(1):89-96.

15. Campanale CM, Gioia G Di, Maria S Di, Marullo F, Fittipaldi M, Creta A, et al. Prevalence of rheumatic heart disease in North Madagascar: An echocardiographic screening in young and adult populations. Australas Med J.2017 Aug;10(7):620-7.

16. Koirala PC, Sah RK, Sharma D. Pattern of rheumatic heart disease in patients admitted at tertiary care centre of Nepal. Nepal Hear J. 2018;15(1):29-33.

17. Kafle RC, Alurkar VM, Paudel N, Jha GS. Pattern of valvular involvement in rheumatic heart disease patients in a Tertiary Care Hospital of Western Nepal. Nepal Hear J. 2016;13(2):2931.
18. Koju R, Gurung R, Pant P, Pokharel B, Bedi T. Pattern of heart valve involvement in rheumatic heart disease. Nepal Hear J. 2017 Nov;6(1):17-22.

19. Aurakzai HA, Hameed S, Shahbaz A, Gohar S, Qureshi M, Khan H, et al. Echocardiographic profile of rheumatic heart disease at a tertiary cardiac centre. J Ayub Med Coll Abbottabad. 2009;21(3):122-126.

20. Laudari S, Subramanyam G. A study of spectrum of rheumatic heart disease in a tertiary care hospital in Central Nepal. IJC Hear Vasc. 2017 Jun;15:26-30.

21. Manjunath CN, Srinivas P, Ravindranath KS, Dhanalakshmi C. Incidence and patterns of valvular heart disease in a tertiary care high-volume cardiac center: A single center experience. Indian Heart J. 2014;66(3):320-6. 